\title{
Perbaikan Kualitas Produk Tas Kulit dengan Menggunakan Metode Teorija Rezhenija Izobretatelskih Zadach (TRIZ) pada CV. X - Bandung
}

\author{
Mochammad Iqbal Syidik*, Iyan Bachtiar \\ Prodi Teknik Industri, Fakultas Teknik, Universitas Islam \\ Bandung, Indonesia. \\ *iqbalsyidik123@gmail.com, iyan.bachtiar@unisba.ac.id
}

\begin{abstract}
CV. X is a company engaged in the leather industry that manufactures wallets, bags and key chains. The company experienced a decrease in sales volume due to a decrease in product quality from defective products in the company. Leather bags have an average percentage of disability of 2.39\% in 2017-2018 from the company's disability limit of 2\%. The existence of these defective products requires companies to improve product quality to reduce the occurrence of defects. The method used to solve the problems that are being faced by the company is the Seven Tools Quality Control method to identify the causes of product defects, while the Rezhenija Izobretatelskih Zadach (TRIZ) method is used to design a product quality improvement plan. The result of data processing which becomes the main priority is defect cutting. The causes of cutting defects include decreased work concentration, inadequate workers, poor physical condition, no machine maintenance, blunt cutting machines, high cutting machine use intensity, work environment, hot room temperature, lack of work space lighting. All causes of product defects are designed to improve the quality of leather bag products by creating visual controls, forms for worker health, cutting knife replacement machines, installing air conditioners, and adding lights to the sewing machine.
\end{abstract}

Keywords: Quality Control, Seven Tools Quality Control, Rezhenija Izobretatelskih Zadach's Theory.

\begin{abstract}
Abstrak. CV. X merupakan perusahaan yang bergerak di bidang industri kulit yang memproduksi dompet, tas, dan gantungan kunci. Perusahaan mengalami penurunan volume penjualan yang disebabkan karena adanya penurunan kualitas produk dari produk cacat di perusahaan. Tas kulit memiliki rata-rata persentase kecacatan sebesar 2,39\% pada tahun 2017-2018 dari batas kecatatan yang ditetapkan perusahaan sebesar $2 \%$. Adanya produk cacat tersebut mengharuskan perusahaan melakukan perbaikan kualitas produk untuk mengurangi terjadinya kecacatan. Metode yang digunakan untuk menyelesaikan permasalahan yang sedang dihadapi oleh perusahaan yaitu metode Seven Tools Quality Control untuk mengidentifikasi penyebab terjadinya kecacatan produk, sedangkan metode Teorija Rezhenija Izobretatelskih Zadach (TRIZ) digunakan untuk membuat rancangan perbaikan kualitas produk. Hasil pengolahan data yang menjadi prioritas utama yaitu cacat potong. Penyebab cacat potong diantaranya yaitu konsentrasi kerja menurun, pekerja kurang hati-hati kondisi fisik kurang baik, tidak ada perawatan mesin, mesin potong tumpul, intesitas penggunaan mesin potong tinggi, lingkungan kerja, suhu ruangan panas, pencahayaan ruang kerja kurang. Semua penyebab cacat produk dibuat rancangan perbaikan untuk meningkatkan kembali kualitas produk tas kulit dengan membuat visual control, form untuk kesehatan pekerja, mesin penggantian pisau potong, pemasangan $\mathrm{AC}$, serta penambahan lampu pada mesin jahit.
\end{abstract}

Kata Kunci: Pengendalian Kualitas, Seven Tools Quality Control, Teorija Rezhenija Izobretatelskih Zadach. 


\section{A. Pendahuluan}

Dalam aspek tata busana dan produk hewan, kulit adalah bahan yang fleksibel dan tahan lama yang dibuat dengan proses penyamakan kulit hewan, umumnya kulit sapi. Kulit telah digunakan sebagai bahan baku pembuatan pakaian, interior kendaraan, furniture, sampul buku, bedug, dan sebagainya. Indonesia mengalami kenaikan nilai ekspor produk kulit sebesar 6,28\% terhadap total ekspor industri pengolahan sepanjang Januari-Juni 2018 (Badan Pusat Statistik, 2018). Adapun sepuluh komoditi hasil industri pengolahan dengan nilai ekspor terbesar pada tahun 2018 dapat dilihat pada Gambar 1.1.

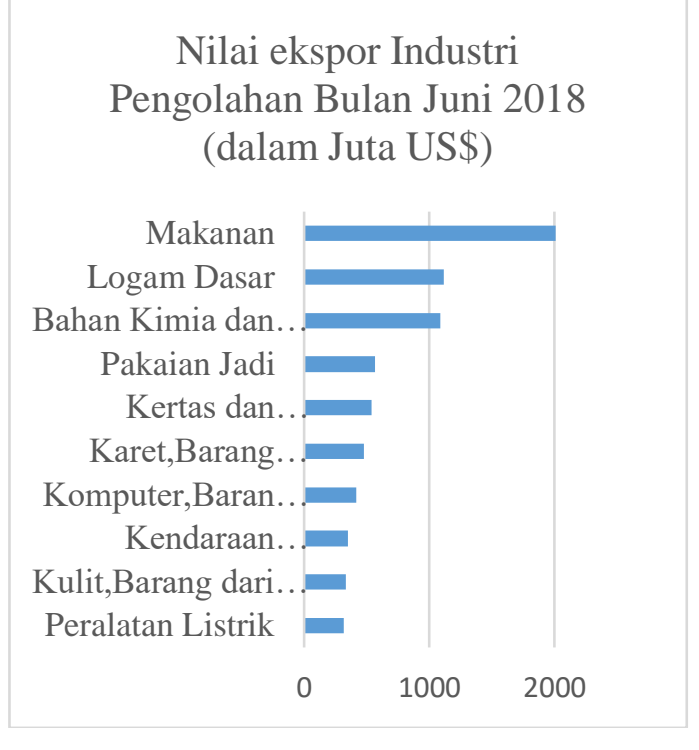

Gambar 1. Nilai Ekspor Industri

Berdasarkan Gambar 1.1 menunjukkan bahwa industri kulit berapa diposisi ke 9 dari 10 jenis komoditi hasil industri pengolahan, artinya industri kulit masih memiliki eksistensi pada industri pengolahan.

Salah satu contoh industri pengolahan bahan kulit adalah CV. X. CV. X merupakan perusahaan yang bergerak di bidang industri pengolahan kulit dengan berbagai jenis dan model produk, yaitu tas, dompet dan gantungan kunci yang ada di Bandung.

Kendala yang dihadapi perusahaan salah satunya adalah terdapatnya produk cacat pada tas kulit yang terdampak pada penurunan kualitas produk batas maksimal toleransi yang ditetapkan perusahaan sebesar $2 \%$.

Metode yang digunakan untuk memperbaiki kualitas produk yaitu menggunakan metode seven quality control tools dan untuk memberikan usulan perbaikan digunakan metode TRIZ. Berdasarkan uraian latar belakang diatas, maka dapat diidentifikasi permasalahan dalam penelitian ini sebagai berikut:

1. Permsalahan apa yang terjadi pada proses produksi tas kulit?

2. Apa penyebab utama kecacatan pada proses produksi tas kulit?

3. Bagaimana merancang perbaikan kualitas pada proses produksi tas kulit?

\section{B. Landasan Teori}

The seven quality control tools adalah alat-alat bantu yang bermanfaat untuk memetakan lingkup persoalan, menyusun data dalam diagram-diagram agar lebih mudah untuk dipahami, menelusuri berbagai kemungkinan penyebab persoalan dan memperjelas kenyataan atau fenomena yang otentik dalam suatu persoalan.

Pada dasarnya terdapat tujuh alat yang biasa disebut sevenquality control tools yang dapat dipergunakan dalam pengendalian kualitas yaitu: Checksheet, 
Histogram, Stratifikasi, Peta Kendali (Control Chart), Diagram Pencar, Diagram Pareto, dan Diagram Sebab-Akibat.

\section{TEORIJA REZHENIJA IZOBRETATELSKIH ZADACH (TRIZ)}

TRIZ merupakan metode perbaikan berdasarkan ide yang dapat menyelesaikan permasalahan yang kontradiktif meningkatkan keidealan sistem dan mempergunakan sumber yang tersedia (Rantanen, Conley, dan Domb, 2018). Menurut Assauri (2008) tahapan metode TRIZ yaitu 39 parameter, matriks kontradiksi, 40 prinsip.

\section{Hasil Penelitian dan Pembahasan}

Pengolahan data dilakukan dengan mengidentifikasi kecacatan, menentukan jenis kecacatan dengan menggunakan diagram pareto, dan mengidentifikasi masalah penyebab kecacatan dengan menggunakan fishbone. Kemudian mengkategorikan faktor penyebab kecacatan menggunakan 39 parameter TRIZ, membuat matris kontradiksi, dan menemukan solusi ideal dengan 40 prinsin kreatif TRIZ.

\section{Identifikasi Masalah}

1. Checksheet

Checksheet berguna untuk mempermudah proses pengumpulan data serta analisis. Berdasarkan gambar 1 terdapat 1 jenis kecacatan yang memiliki nilai tertinggi.

\begin{tabular}{|c|c|c|c|c|c|c|c|}
\hline \multirow[b]{2}{*}{ Tanggal } & \multicolumn{5}{|c|}{ Jenis cacat } & \multirow[b]{2}{*}{ Total cacat } & \multirow{2}{*}{$\begin{array}{c}\text { Total } \\
\text { produksi }\end{array}$} \\
\hline & $\begin{array}{c}\text { Cacat } \\
\text { potong }\end{array}$ & $\begin{array}{c}\text { Cacat jahit } \\
\text { tangan }\end{array}$ & $\begin{array}{c}\text { Cacat jahit } \\
\text { mesin }\end{array}$ & $\begin{array}{c}\text { Cacat } \\
\text { aksesoris }\end{array}$ & $\begin{array}{l}\text { Cacat } \\
\text { kotor }\end{array}$ & & \\
\hline 1 & 1 & & & & & 1 & 36 \\
\hline 2 & 1 & & & & & 1 & 39 \\
\hline 3 & 1 & 1 & 1 & & & 3 & 27 \\
\hline 4 & & & & 1 & & 1 & 37 \\
\hline 5 & 1 & & & & & 1 & 35 \\
\hline 6 & 1 & 1 & & & 1 & 3 & 40 \\
\hline 7 & & & 1 & & & 1 & 32 \\
\hline 8 & 1 & & & & 2 & 3 & 25 \\
\hline 9 & & & & 2 & & 2 & 35 \\
\hline 10 & & & 1 & & 1 & 2 & 40 \\
\hline 11 & & & & & & 0 & 32 \\
\hline 12 & & 1 & & 1 & & 2 & 29 \\
\hline 13 & 2 & 1 & & & & 3 & 30 \\
\hline 14 & 1 & & & & & 1 & 30 \\
\hline 15 & 1 & & & & 2 & 3 & 28 \\
\hline 16 & & & & 1 & & 1 & 38 \\
\hline 17 & & 1 & & & & 1 & 42 \\
\hline 18 & & & & & & 0 & 42 \\
\hline 19 & & & & 1 & 1 & 2 & 40 \\
\hline 20 & 1 & & & & & 1 & 35 \\
\hline 21 & & & & & 1 & 1 & 39 \\
\hline 22 & & & 1 & & & 1 & 43 \\
\hline 23 & 1 & & & 1 & 1 & 3 & 35 \\
\hline 24 & & & & & & 0 & 30 \\
\hline 25 & 1 & 1 & & & & 2 & 40 \\
\hline 26 & & & 1 & & 1 & 2 & 32 \\
\hline 27 & 1 & & & 1 & & 2 & 23 \\
\hline 28 & 2 & & & & & 2 & 34 \\
\hline 29 & & & & & & 0 & 30 \\
\hline 30 & & & & 1 & & 1 & 22 \\
\hline Jumlah & 16 & 6 & 5 & 9 & 10 & 46 & 1020 \\
\hline
\end{tabular}

Gambar 1 Checksheet 
2. Diagram Pareto

Diagram pareto berguna untuk memilih masalah-masalah utama

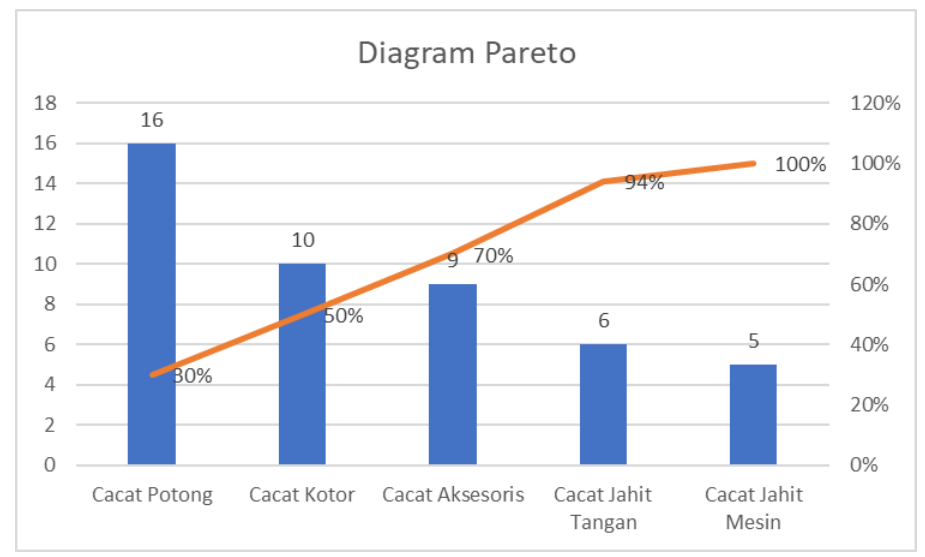

Gambar 2 Diagram Pareto

3. Diagram Sebab-Akibat Fishbone

Dilakukan identifikasi terhadap penyebab terjadinya kecacatan tas kulit yang menjadi masalah utama dari hasil checksheet dan diagram pareto. Diagram sebab akibat ini akan membantu dalam penyeledikan atau pencarian fakta serta membangkitkan ide-ide, yang nantinya akan mempermudah dalam memberikan suatu usulan perbaikan. Diagram sebab akibat cacat tas kulit dapat dilihat pada gambar 3.

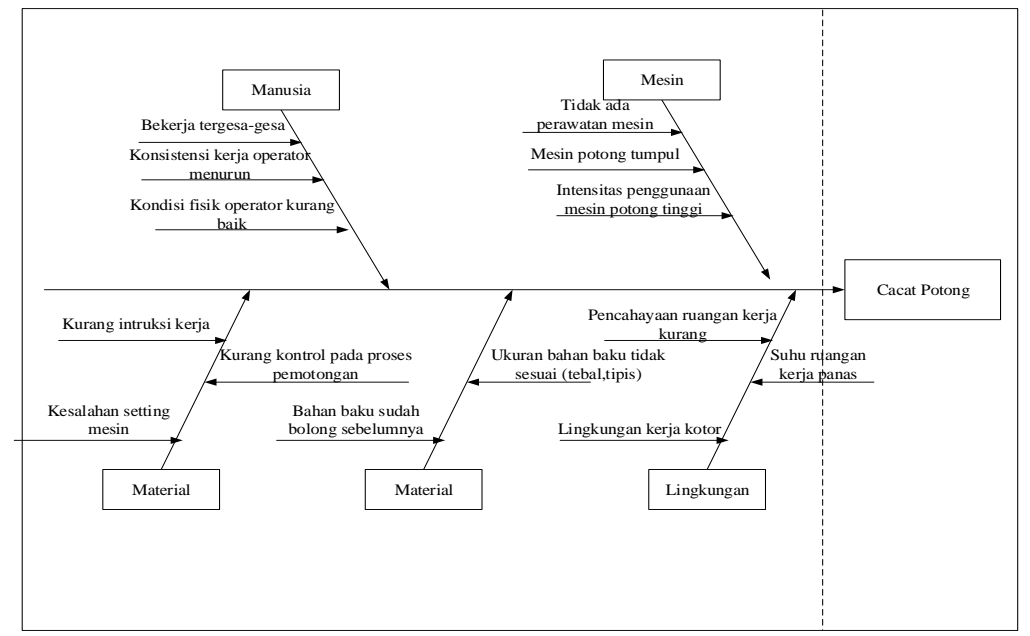

Gambar 3 Fishbone Cacat Potong

Usulan Perbaikan

1. Pengklasifikasian factor penyebab kecacatan tas kulit

Permasalahan yang terpilih cacat potong yang akan ditentukan improving feature sebagai parameter yang ingin ditingkatkan atau diperbaiki dan worsening feature sebagai parameter yang memburuk akibat dari adanya peningkatan atau perbaikan tersebut. 
Tabel 2. Faktor Penyebab Kecacatan Tas Kulit

\begin{tabular}{|c|l|l|l|}
\hline $\mathrm{N}_{0}$ & \multicolumn{1}{|c|}{ Faktor Penyebab Kecacatan Tas Kulit } & \multicolumn{1}{|c|}{ Improved Parameter } & Worsened Parameter \\
\hline 1 & Konsentrasi kerja menurun & (14) strength & (22) lost of energy \\
\hline 2 & Bekerja kurang hati-hati & (14) strength & (22) lost of energy \\
\hline 3 & Kondisi fisik kurang baik & (14) strength & (25) lost oftime \\
\hline 4 & Tidak ada perawatan mesin & (27) reliability & (11) stress or pressure \\
\hline 5 & Mesin potong tumpul & (12) Shape & (23) Loss of substance \\
\hline 6 & Intensitas penggunaan mesin potong tinggi & (27) reliability & (37) difficulty of detecting and measuring \\
\hline 7 & Ukuran bahan baku tidak sesuai (tebal/tipis) & (29) accuracy of manufacturing & (37) difficulty of detecting and measuring \\
\hline 8 & Bahan baku sudah bolong sebelumnya & (29) accuracy ofmanufacturing & (37) difficulty ofdetecting and measuring \\
\hline 9 & Kurang intruksi kerja & (14) strength & (22) lost of energy \\
\hline 10 & Kesalahan setting mesin & (27) reliability & (11) stress or pressure \\
\hline 11 & Kurang kontrol pada proses pemotongan & (29) accuracy ofmanufacturing & (37) difficulty of detecting and measuring \\
\hline 12 & Lingkungan kerja kotor & (27) reliability & (22) loss of energy \\
\hline 13 & Suhu rungan panas & (17) temperature & (20) use of energy by stationary object \\
\hline 14 & Pencahayaan ruang kerja kurang & (18) illumination intensity & (20) use of energy by stationary \\
\hline
\end{tabular}

2. Matriks Kontradiksi

Matriks kontradiksi membantu dalam menemukan kumpulan solusi berdasarkan 40 prinsip kreatif yang ada pada metode TRIZ.

Tabel 2. Matriks Kontradiksi

\begin{tabular}{|c|c|c|c|c|c|c|c|}
\hline \multirow{2}{*}{ NO } & Worsened Feature & 11 & 20 & 22 & 23 & 25 & 37 \\
\hline & Improved Feature & Stress or pressure & $\begin{array}{l}\text { Use of energy by } \\
\text { stationary object }\end{array}$ & Lost of energy & $\begin{array}{c}\text { Loss of } \\
\text { substance }\end{array}$ & Lost of time & $\begin{array}{l}\text { Diffculty of } \\
\text { detecting and }\end{array}$ \\
\hline 12 & & $34,15,10,14$ & All & 14 & $35,29,3,5$ & $14,10,34,17$ & $15,13,39$ \\
\hline 14 & Strengl & $10,3,18,40$ & 35 & 35 & $35,28,31,40$ & $29,3,28,10$ & $27,3,15,40$ \\
\hline 17 & $\mathrm{Te}$ & $35,39,19,2$ & All & $21,17,35,38$ & $21,36,29,31$ & $35,28,21,18$ & $3,27,35,31$ \\
\hline 18 & illumination intensity & All & $32,35,1,15$ & $13,16,1,6$ & 31,1 & $19,1,26,17$ & 32,15 \\
\hline 27 & & $10,24,35,19$ & 36,23 & $10,11,35$ & $10,35,29,39$ & $10,30,4$ & $27,40,28$ \\
\hline 29 & ccuracy of Manufacturin & 3,35 & All & $13,32,2$ & $35,31,10,2$ & $32,26,28,18$ & All \\
\hline
\end{tabular}


3. Usulan perbaikan

Pada tahap ini akan dilakukan pemilihan solusi yang paling ideal berdasarkan angkaangka yang telah diperoleh pada matriks kontradiksi.

Tabel 3. Usulan Perbaikan

\begin{tabular}{|c|c|c|}
\hline \multirow{2}{*}{ No } & Faktor Penyebab Kecacatan & Usulan Perbaikan \\
\hline 1 & Konsentrasi kerja menurun & Membuat visual control \\
\hline 2 & Bekerja kurang hati-hati & Membuat visual control \\
\hline \multirow{2}{*}{3} & Kondisi fisik kurang baik & Membuat visual control \\
\cline { 3 - 3 } & & Membuat form untuk kesehatan pekerja \\
\hline \multirow{2}{*}{4} & Tidak ada perawatan mesin & Membuat from untuk perawatan mesin \\
\cline { 3 - 3 } & Mesin potong tumpul & Membuat jadwal untuk perawatan mesin \\
\hline 5 & Intensitas penggunaan mesin potong tinggi & Membuat form penggantian alat potong \\
\hline 6 & Bahan baku bolong sebelumnya & Membuat SOP setting mesin potong \\
\hline 7 & Kurang instruksi kerja & Membuat form pengecekkan bahan baku \\
\hline 8 & Kesalahan setting mesin & Meningkatkan komunikasi antar pekerja serta pelatihan \\
\hline 9 & Luran bahan baku tidak sesuai (tebal/ tipis) & Membuat form pengecekan mesin \\
\hline 10 & Suhu ruangan panas & Membuat form pengecekkan bahan baku \\
\hline 11 & Pencahayaan ruang kerja kurang & Membuat visual control \\
\hline 12 & & Penerapan pemasangan AC \\
\hline 13 & & penambahan lampu pada mesin jahit \\
\hline 14 & &
\end{tabular}

\section{Kesimpulan}

Berdasarkan hasil penelitian dan pengolahan data yang dilakukan, maka dapat ditarik kesimpulan sebagai berikut:

1. Penyebab terjadinya kecacatan pada produk tas kulit di CV. X dipengaruhi oleh beberapa faktor yaitu manusia, mesin, material, dan lingkungan.

2. Penyebab utama di CV. X adalah cacat potong.

3. Meningkatkan pengawasan dalam bekerja melakukan pemeriksaan mesin secara berkala, melakukan pemasangan ac, dan memasang lampu led pada mesin jahit.

\section{E. Saran}

1. Meningkatkan pengawasan dalam melakukan pengecekan kualitas produk.

2. Memperhatikan kinerja operator.

3. Melakukan perbaikan serta pengecekan berkelanjutan dan dilakukan dengan konsisten.

4. Penelitian selanjutnya diharapkan dapat menguraikan mengenai kerugian biaya akibat produk cacat yang ditimbulkan dan lebih banyak mengkaji sumber literatur terkait.

\section{Daftar Pustaka}

[1] Assauri, S., 2008. Manajemen Produksi dan Operasi. Edisi Revisi. Jakarta: Fakultas Ekonomi Universitas Indonesia.

[2] Badan Pusat Statistik, 2018. Perkembangan Ekspor Dan Impor Indonesia Juni 2018. Jakarta: Badan Pusat Statistik.

[3] Badan Pusat Statistik, 2018. Statistik Perdagangan Luar Negeri: Ekspor. Jakarta: Badan Pusat Statistik.

[4] Badan Pusat Statistik Provinsi Jawa Barat, 2018. Statistik Industri Besar Dan Sedang Jawa Barat. Bandung: Badan Pusat Statistik Provinsi Jawa Barat.

[5] Rantanen, K., Conley, D. W., dan Domb, E. R., 2018. Simplified TRIZ: New Problem Solving Applications for Engineers and Manufacturing Professionals. 3rd ed.

[6] Sari, Diana P dan Andry H. 2013. "Usulan Perbaikan KualitasPelayanan Pada Instalasi Rawat Jalan Dengan Metode Servqual Dan Triz (Studi Kasus Di Rs Muhammadiyah Roemani)" dalam Jurnal Teknik Industri, Vol 7 No. 2. 